Virginia Commonwealth University vCU Scholars Compass

2009

\title{
Dental Anatomy Carving Computer-Assisted Instruction Program: An Assessment of Student Performance and Perceptions
}

Elizabeth T. Nance

Virginia Commonwealth University

Sharon K. Lanning

Virginia Commonwealth University, sklanning@vcu.edu

John C. Gunsolley

Virginia Commonwealth University, jgunsolley@vcu.edu

Follow this and additional works at: http://scholarscompass.vcu.edu/peri_pubs

Part of the Periodontics and Periodontology Commons

Reprinted by permission of Journal of Dental Education, Volume 73, 8 (August 2009). Copyright 2009 by the American Dental Education Association.

\section{Downloaded from}

http://scholarscompass.vcu.edu/peri_pubs/3

This Article is brought to you for free and open access by the Dept. of Periodontics at VCU Scholars Compass. It has been accepted for inclusion in Periodontics Publications by an authorized administrator of VCU Scholars Compass. For more information, please contact libcompass@vcu.edu. 


\title{
Dental Anatomy Carving Computer-Assisted Instruction Program: An Assessment of Student Performance and Perceptions
}

\author{
Elizabeth T. Nance, D.D.S., M.S.H.A., F.A.G.D.; Sharon K. Lanning, D.D.S.; \\ John C. Gunsolley, D.D.S., M.S.
}

Abstract: The purpose of this study was to compare the performance of students exposed to two different instructional modalities for dental anatomy wax carving: CAI (computer-assisted instruction) using DVD technology, or traditional laboratory instruction. Students' self-assessment scores were also compared to faculty scores, and students' perceptions of their teaching modality were analyzed. Seventy-three first-year dental students (response rate 81 percent) participated in this randomized single blind trial, in which faculty graders were blinded to student group assignment. There were no statistical differences, as determined by the Wilcoxon non-parametric test and a t-test, between the faculty grades on the wax carving from the two teaching methods the students experienced. The student self-assessments revealed higher mean grades (3.0 for the DVD-only group and 3.1 for the traditional group) than the faculty actual mean grades (2.2 for both the DVD-only group and the traditional group) by almost one grade level on a 4.0 grade scale. Similar percentages of students in the traditional group had either favorable or unfavorable perceptions of their learning experience, while more students in the DVD-only group reported favorable perceptions. Students from both groups said they wanted more faculty feedback in the course. Based on these objective and subjective data, merging CAI and traditional laboratory teaching may best enhance student learning needs.

Dr. Nance is Assistant Professor, Department of General Practice; Dr. Lanning is Associate Professor, Department of Periodontics; and Dr. Gunsolley is Professor, Department of Periodontics - all at Virginia Commonwealth University School of Dentistry. Direct correspondence and requests for reprints to Dr. Elizabeth T. Nance, School of Dentistry, Virginia Commonwealth University, 520 N. 12 ${ }^{\text {th }}$ Street, P.O. Box 980566, Richmond, VA 23298-0566; 804-828-2977 phone; 804-828-3159 fax; etnance@vcu.edu.

Key words: dental education, computer-assisted instruction, morphology, randomized controlled trial, self-assessment, student perceptions, dental anatomy

Submitted for publication 1/16/09; accepted 3/2/09

$\mathrm{C}$ omputer technologies have been used to enhance learning since the $1960 \mathrm{~s}^{1,2}$ Advancements in technology and greater acceptance by students have fostered its use in dental education. ${ }^{3}$ Computer-assisted instruction (CAI) is an example of blending technology to enhance education. Its advantages for anytime anywhere access provide flexibility for the independent adult learner. CAI can present material in new and innovative ways, while allowing students to learn at their own pace. CAI allows material to be reviewed multiple times in contrast to traditional instructor-directed learning, which is frequently delivered only once. Furthermore, CAI has the potential to lessen faculty workload as it allows archived, retrievable instruction.

Student perceptions of the effectiveness of computer-aided learning compared to conventional teaching vary. ${ }^{4}$ Fouad and Burleson ${ }^{5}$ reported that students preferred using computer assistance for learning, but opinions differed on its effectiveness when compared with traditional teaching. Students in Hobson et al.'s $\mathrm{s}^{6}$ and McDonough and Marks's ${ }^{7}$ studies felt that their educational needs were better served by a personal tutorial or face-to-face teaching rather than computer instruction. Other studies have suggested that students prefer technology as a supplement to traditional didactic sessions. ${ }^{8,9}$ Another study found similar satisfaction and educational results using either computer-aided or tutor-delivered teaching alone with no advantage of using them in tandem. ${ }^{10}$ Reasons for these research variations include, but are not limited to, differences in subject matter, presentation mode of material, students' familiarity and comfort with computer technology, and differences in the ways students learn.

Previously at Virginia Commonwealth University School of Dentistry (VCU SOD), the didactic teaching of dental anatomy and morphology utilizing an interactive computer program was found to be as effective as teaching with traditional lectures. ${ }^{11}$ In that study, equivalence testing was used to compare the effectiveness of these two teaching approaches. Equivalence testing can be used to compare a new modality to an established one, particularly when the new modality offers economic and logistical advantages. ${ }^{12}$ Equivalence testing was also used in our 
study to investigate the effectiveness of another type of CAI utilizing a DVD demonstrating wax carving. The primary aim of our study was to determine the equivalence of CAI to traditional laboratory instruction in the area of dental anatomy wax carving. Additional aims were to evaluate the accuracy of students' self-assessments using faculty grades as the course benchmark and students' perceptions of the teaching mode to which they were exposed.

\section{Methods}

After approximately six weeks of lectures on specific tooth anatomy and morphology, first-year dental students (D1s) began laboratory sessions in which they learned to manipulate and carve wax to duplicate model plastic teeth. After initial instruction in carving instrument usage and basic carving techniques, they carved five practice teeth in wax. Students were given approximately two weeks to practice each wax carving before taking a wax carving competency exam. During the exam, students worked independently in a secured environment. Each student's lowest wax carving grade was dropped prior to determining his or her final grade.

The CAI instructional DVD is a one-hour, step-by-step reproduction of a tooth $\# 5$ in wax. It demonstrates and explains the carving of tooth \#5 beginning with the use of carving instruments, to the wax block-out procedures, and continuing through to the last steps of polishing the wax tooth. The CAI DVD is PC and Apple compatible. It can be advanced, rewound, and stopped depending on the needs of the student for carving instruction and demonstration.

This randomized, controlled, single blind trial was approved by the VCU Office of Research Subjects Protection. Volunteers were recruited from the entire D1 class (ninety students) by announcements and an informational meeting to explain participation in the study. Informed volunteers who agreed to participate were randomly assigned into either the CAI DVD-only group or the traditional group using simple randomization. Simple randomization was achieved by using a computer to randomly assign participants to either group. Faculty graders were blinded as to which group students belonged.

\section{Study Design}

We wanted to limit students' exposure to a new teaching modality in case it was found to be inferior to the traditional method, so we decided to have students carve tooth $\# 5$, the second from last tooth to be carved, for the purposes of this study. This decision was made for several reasons. First, it was felt that, at that point in the course, students would be experienced with basic waxing techniques, allowing greater focus on the anatomical characteristics of the tooth. Secondly, students would be familiar with the grading rubric and better able to self-assess their work. Additionally, students would be familiar with course protocol and logistics. Lastly, by placing the study later in the course, it was assumed that the students' trust and familiarity with the faculty would enhance their understanding of the importance of the study and thus increase their willingness to participate.

The traditional group attended required carving labs staffed by faculty and senior dental students serving as teaching assistants. Although students in this group had access to instructional handouts, they did not have the carving instruction technology DVD. The instructional handout consisted of stepby-step carving instructions along with illustrations for duplicating a model tooth in wax. Students in this group were asked not to share their learning materials with the DVD-only group. Course protocol dictated that students in the traditional group must submit a "practice" carving to faculty for evaluation and must earn a passing grade before taking the wax carving competency exam. Students who chose not to participate in the study attended the traditional lab and followed its protocol.

The DVD-only group did not attend scheduled labs. They utilized the technique DVD to instruct them in the carving of tooth \#5. These students were given access to work space in nonscheduled labs but did not receive handouts or faculty feedback. Students in the DVD-only group were instructed not to share any information demonstrated on the DVD with the traditional group. The DVD-only group was not given an instructional handout, nor did they submit a "practice" tooth for faculty evaluation prior to taking the wax carving competency exam.

The competency exam was scheduled at the end of two weeks of either the DVD-only or traditional laboratory instruction, at which time students simultaneously submitted a colored competency wax carving for faculty grading, competency self-assessment sheet, and student satisfaction survey (described below). Student anonymity was protected since the color of the carving wax was identical for all students and only a numerical code identified individual carvings, self-assessments, and surveys. Only students 
who had agreed to participate in the research had data entered into the study database.

\section{Grading Rubric and Student Satisfaction Survey}

To maximize grading standardization, various aspects of the carving were assessed using a grading rubric handout. This handout required assessment of the carving from multiple views including labial, mesial, lingual, distal, and occlusal. The carving was assessed as to its replication of the model tooth in dimension, anatomical landmarks, and finishing.

Faculty members and students were given identically detailed grading descriptor rubrics with criteria and grade level suggestions. The general grade descriptors were as follows: 4.0 (excellent work), 3.5 (outstanding work), 3.0 (good work), 2.5 (above average work), and 2.0 (average work). Any grade less than 2.0 was deemed unsatisfactory, unacceptable, or failing.

Based on specific criteria, the student and faculty member were to derive a grade for the carving ranging from 0 to 4 inclusive. The grading scale was $\mathrm{A}=4.0-3.4, \mathrm{~B}=3.39-2.8, \mathrm{C}=2.7-2.0$, and $\mathrm{F}=$ any number below 2.0. Fractions of these numerals were permitted.

All students self-assessed and graded their competency carvings before submitting them for faculty grading. The same rubric was used by students and faculty. This was the first time the students performed formal self-assessment of their work using the grading rubric.

A survey was developed by the course director (lead author) and was critiqued and reviewed by a faculty member with experience in survey design and content area (second author). The survey gathered demographic data including gender, age, and ethnicity. Additional survey items inquired about years of post-college education, past dental profession experience, self-perceived learning style, past activity with computer technology and CAI, comfort level, perception of usefulness of teaching method for his or her learning style, perception of quality of carving utilizing a specific instruction method, assessment of time allocated for the instruction, and level of satisfaction with instructional method. The majority of the survey items prompted students to select their responses from ordinal scales, but four items were open-ended. These qualitative assessment items prompted students to offer their perceptions on how the instructional method they were exposed to could be improved and what they liked most and least about the instructional method. Student comments were read by two reviewers who agreed on themes and tallied the frequency of responses.

\section{Statistical Methods and Data Analysis}

The first step of the data analysis was to investigate how well the randomization produced groups with equivalent characteristics. The data groups were compared on the basis of racial, gender, and age distribution. For dichotomous data, Fisher's exact test was used, and for categorical data the Pearson chi-square goodness of fit test analysis was used.

The next step was to test the major underlying hypothesis of the study, which was whether the teaching mode had an effect on the grade received for the wax carving exercise. The Wilcoxon rank sum test was used to test this hypothesis.

The post hoc power analysis was based on the assumptions that the mean grades for the groups were 3.1 for the traditional group and 3.0 for the DVD-only group (on a 4-point scale), with a common within-group standard deviation of 0.5 , that the sample sizes in the two groups were thirty-six and thirty-seven, and that the alpha was .05. For these assumptions the study has power of 79 percent to exclude a mean difference between groups of 0.4 points in either direction.

The data from the survey were evaluated to determine if the groups were similar in experience and/or if their perceptions of the exercise were similar. Pearson chi-square goodness of fit test analysis was used to analyze each item on the survey.

The last aspect of the analysis was to compare faculty-generated grades and grades obtained through student self-assessment. Spearman correlations were calculated for this relationship within each group. Additionally, regression coefficients were calculated between the two measures within each group and the interaction between the two estimates. The interaction was modeled to test whether the relationships between the two types of assessment were consistent for both groups.

\section{Results}

Seventy-three of ninety students enrolled in the course (response rate 81 percent) chose to participate in the research study. The seventy-three 
participants were randomized into two study groups: thirty-seven in the DVD-only group and thirty-six in the traditional group. The groups were balanced on the basis of gender and age distribution (Table 1). Racial distribution of the two groups could not be investigated since only nineteen of the seventy-three students provided responses for this item on the survey (survey item 3). Thus, groups were balanced for the demographic data that was available.

There were no statistically significant differences between faculty grades on wax carving and students' self-assessments of their own wax carvings based on the teaching modality they experienced as determined by the Wilcoxon non-parametric test and a t-test (Table 2). A post hoc power analysis was done to determine the least significant difference between groups that could be found. The post hoc power analysis revealed that a mean difference in grades between groups of .40 could have been found at 79 percent power. Thus, a difference of approximately one-half of a grade point or increment could have been found in this study.

The students' self-assessments revealed a higher mean grade on their performance in both groups (3.0 for the DVD-only group and 3.1 for the traditional group) than the faculty actual mean grades ( 2.2 for each group) by almost one grade level. There was also a statistically significant correlation difference between students' self-assessments and faculty grades $(\mathrm{P}<0.006)$, but the relationship was relative weak (Spearman's correlation 0.32) (Figure 1).

The two student learning groups responded in a similar fashion to items that dealt with training prior to dental school, perceived learning styles, and experience with computer and DVD technologies, with only one exception (Table 3). In the DVD-only group, significantly more students $(\mathrm{P}<0.02)$ indicated they had worked "extensively" $(n=17)$ with computer technology than did the traditional group $(n=9)$.

Survey items 12 through 18 (Table 4) dealt with students' perceptions and opinions of their learning experiences. In items 12, 13, 17, and 18, more students in the traditional group (22 to 31 percent) disagreed with these survey items than did students in DVD-only group (zero to 5 percent). The items that were statistically different were
Table 1. Gender and age distribution of the two student groups in study, by number and percentage of students in each group (DVD-only=37; traditional=36)

\begin{tabular}{lcc} 
& $\begin{array}{c}\text { DVD-Only } \\
\text { N }(\%)\end{array}$ & $\begin{array}{c}\text { Traditional } \\
\text { N }(\%)\end{array}$ \\
\hline Gender (Females) & $17(46 \%)$ & $18(50 \%)$ \\
Age $(>26)$ & $10(27 \%)$ & $11(31 \%)$ \\
\hline
\end{tabular}

Table 2. Faculty grades and students' self-assessments of wax carvings, by student group (mean \pm std err)

\begin{tabular}{lccc} 
Group & N & $\begin{array}{c}\text { Faculty } \\
\text { Grade }\end{array}$ & $\begin{array}{c}\text { Self-Assessment } \\
\text { Grade }\end{array}$ \\
\hline DVD-Only & 37 & $2.2 \pm 0.1$ & $3.0 \pm 0.1$ \\
Traditional & 36 & $2.2 \pm 0.1$ & $3.1 \pm 0.1$ \\
\hline
\end{tabular}

as follows: the teaching method worked well for their learning style $(\mathrm{P}<0.05)$, improved their ability for self-directed learning $(\mathrm{P}<0.05)$, improved their ability to self-assess their performance $(\mathrm{P}<0.05)$, and was adequate $(\mathrm{P}<0.01)$, and they enjoyed the teaching method $(\mathrm{P}<0.002)$. In the traditional group, 28 to 42 percent of the students agreed with these items, while 59 to 76 percent of the students in the DVD-only groups agreed. The two groups had similar percentages of students that were neutral about these survey items. Thus, similar percentages of students in the traditional group had either favor-

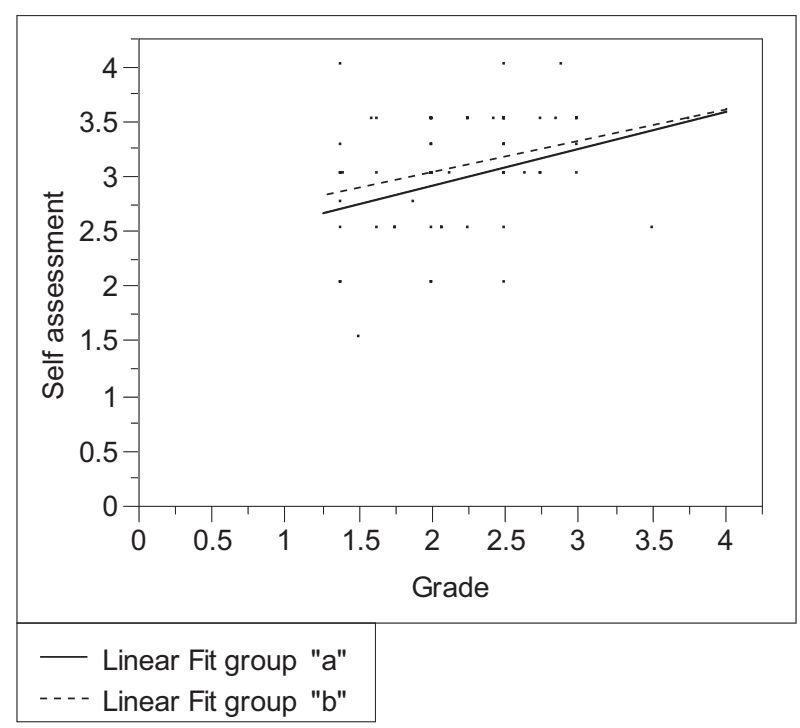

Figure 1. Comparisons of wax carving grades: faculty grade (a) vs. student self-assessment grade (b) 
Table 3. Responses to student survey, items 4-11, by group (DVD-only or traditional)

4. Years of post-college education

Traditional $\quad$ None

DVD-Only

5. Before dental school, I worked as

6. I feel that my learning style is

7. I learn best by

8. Before dental school, I worked with computer technology

9. Before dental school, I worked with computer technology*

10. Before dental school, I was exposed to learning through use of computer technology

11. Before this course, my comfort level with learning with DVD technology was

$$
\begin{aligned}
& \text { Traditional } \\
& \text { DVD-Only }
\end{aligned}
$$

Traditional
DVD-Only

$$
\begin{aligned}
& \text { Traditional } \\
& \text { DVD-Only }
\end{aligned}
$$

$$
\text { Traditional }
$$$$
\text { DVD-Only }
$$$$
\begin{aligned}
& \text { Traditional } \\
& \text { DVD-Only }
\end{aligned}
$$

Dental Assistant$$
\begin{aligned}
& 9 \\
& 7
\end{aligned}
$$

$$
\begin{gathered}
\text { Auditory } \\
1
\end{gathered}
$$$$
0
$$

$$
\begin{gathered}
\text { Self-Directed } \\
\text { Learning } \\
0 \\
2
\end{gathered}
$$

For

$$
\begin{aligned}
& 2 \\
& 2
\end{aligned}
$$

$$
\text { Extensively }
$$

DVD-Only

Traditional DVD-Only

Traditional DVD-Only Hobby
$<1$
3
5

Dental Hygienist 0
0

Visual

6
6

Teacher-

Directed 2
3 Professionally
2

2

Occasionally

27

19

No

10

7

Low

23

18

$* \mathrm{P}<0.02$. All other differences between groups were statistically nonsignificant.

Note: DVD-only $\mathrm{N}=37$; traditional $\mathrm{N}=36$. Variation in number of responses for each question is due to skipped questions.

able or unfavorable perceptions of their learning experience, while more students in the DVD-only group reported favorable perceptions. All students responded similarly to these two items: the quality of their work would have been the same if they had been exposed to the other teaching method, and the right amount of time was allocated for the teaching method.

Students in both the DVD-only (57 percent) and traditional (74 percent) groups stated that their method of instruction could have been improved by greater faculty contact. Eighty-six percent of students in the DVD-only group preferred the flexibility and independence offered by the mode of instruction. Seventy-four percent of students in the traditional group preferred the faculty input. Ninety-four percent of students in the DVD-only group least liked the absence of faculty contact. The top three comments offered by students in the traditional group for what was liked least about the teaching modality were lack of faculty feedback (26 percent), the assigned/manda- tory laboratory session ( 22 percent), and the required satisfactory evaluation on a practice tooth before taking the carving competency exam (18 percent). The remaining comments were not thought to be attributed to the teaching modality.

\section{Discussion}

The primary aim of this study was to determine the equivalence of CAI to traditional laboratory instruction in a dental anatomy wax carving course. Students within the DVD-only group experienced computer-assisted instruction only and were not required to submit a practice tooth for faculty grade prior to taking the competency exam. Students within the traditional group received conventional laboratory teaching materials and experienced faculty instruction and feedback. Students in the traditional group were required to receive a passing grade on a practice carving prior to taking the wax carving competency exam. There was no statistical difference between 
Table 4. Responses to student survey, items 12-18, by group (DVD-only or traditional)

\begin{tabular}{|c|c|c|c|c|c|}
\hline & & Agree & Neutral & Disagree & $\mathrm{P}^{*}$ \\
\hline \multirow{2}{*}{$\begin{array}{l}\text { 12. The teaching method utilized for this waxing worked } \\
\text { well for my learning style. }\end{array}$} & Traditional & 12 & 15 & 9 & \multirow[t]{2}{*}{$<0.05$} \\
\hline & DVD-Only & 22 & 14 & 1 & \\
\hline \multirow{2}{*}{$\begin{array}{l}\text { 13. I feel that the teaching method I was exposed to } \\
\text { improved my ability for self-directed learning. }\end{array}$} & Traditional & 15 & 10 & 11 & \multirow[t]{2}{*}{$<0.05$} \\
\hline & DVD-Only & 22 & 13 & 2 & \\
\hline \multirow{2}{*}{$\begin{array}{l}\text { 14. I feel that the teaching method I was exposed to } \\
\text { improved my ability to self-assess my performance. }\end{array}$} & Traditional & 20 & 9 & 7 & \multirow[t]{2}{*}{$<0.05$} \\
\hline & DVD-Only & 27 & 9 & 1 & \\
\hline \multirow{2}{*}{$\begin{array}{l}\text { 15. I think the quality of my work would have been the } \\
\text { same if I had been exposed to the other teaching } \\
\text { method. }\end{array}$} & Traditional & 15 & 8 & 13 & \multirow[t]{2}{*}{ NS } \\
\hline & DVD-Only & 20 & 10 & 17 & \\
\hline \multirow{2}{*}{$\begin{array}{l}\text { 16. Considering my course load, the right amount of time } \\
\text { was allocated for the teaching method I was exposed to. }\end{array}$} & Traditional & 26 & 4 & 6 & \multirow[t]{2}{*}{ NS } \\
\hline & DVD-Only & 25 & 3 & 9 & \\
\hline \multirow{2}{*}{$\begin{array}{l}\text { 17. The teaching method I was exposed to for wax carving } \\
\text { of } \# 5 \text { was adequate. }\end{array}$} & Traditional & 15 & 13 & 8 & \multirow[t]{2}{*}{$<0.01$} \\
\hline & DVD-Only & 28 & 7 & 2 & \\
\hline \multirow{2}{*}{$\begin{array}{l}\text { 18. I enjoyed the teaching method I was exposed to for } \\
\text { wax carving of } \# 5 \text {. }\end{array}$} & Traditional & 10 & 16 & 10 & \multirow[t]{2}{*}{$<0.002$} \\
\hline & DVD-Only & 24 & 13 & 0 & \\
\hline
\end{tabular}

*The reported $\mathrm{P}$ value is for significant differences between groups. NS=nonsignificant.

carving grades from the two groups. Thus, within the confines of this study, the composite experiences of the two groups produced equivalent outcomes in terms of faculty grading. It appears, therefore, that the practice tooth does not offer substantial benefit to the students' learning process. It may be that the practice tooth combined with CAI would result in a measurable improvement of student performance. However, determining that was beyond the scope of this investigation.

Overall, students provided higher self-assessment scores than the faculty scores that were used as the benchmark grading standard for this course. This difference may be due to unfamiliarity with key anatomical features of tooth anatomy, differences in interpretation of grading criteria, and/or self-inflation of performance by students. Of special note is that five students gave themselves a perfect 4.0 out of 4.0 , and no student graded his or her work as $<2.0$ (failing). The grades given by the faculty ranged from a high of 3.5 to a low of 1.0.

This study supports the anecdotal perception of some VCU faculty members that most students evaluate their work as being of higher quality than the faculty do in their evaluations. This was the first time students in this course were asked to formally evaluate their own work using the grading rubric. Curtis et al. reported that enhancement in students' self-assessment abilities improved their examination scores for some laboratory procedures. ${ }^{13} \mathrm{An}$ assumption is that student self-assessment in formal education positively impacts postgraduate professional services. ${ }^{14}$ Thus, students' repeated formal appraisal of their own wax carvings may calibrate students and faculty, enhance learning, and build self-assessment skills.

Another aspect of this study was the analysis of the students' perceptions of the teaching mode to which they were assigned. Students in the DVD-only group responded more favorably than students in the traditional group. More than half of the DVD-only group agreed that they enjoyed their teaching method. The majority felt it worked well with their learning style and improved their ability for self-directed learning and self-assessment. It may be that the flexibility, conservation of resources, and independence offered by this type of CAI are more desirable in contemporary dental education.

The majority of the students in both the DVDonly and traditional groups provided written comments saying that they wanted more faculty feedback. Students in the traditional group expressing a desire for greater faculty contact was an unexpected finding, especially since the faculty to student ratio increased during the lab sessions involving tooth \#5. That is, the same number of faculty members participated in the course, but they provided instruction to only the students in the traditional group. Since this course involved the students' first wax carving experience, their desire for increased faculty feedback may be 
characteristic of novice learners or may also reflect inadequate self-assessment capabilities.

Most current dental students were born between 1980 and 1994 and are thus considered part of the Internet Generation (Net Gen). By conditioning, Net Gens expect instant educational, social, and informational gratification. Growing computer and Internet capabilities expand the walls of the traditional learning classroom into a virtual learning classroom environment. The challenge is to actively engage these technologically savvy Net Gen learners. For the teaching of dental anatomy carving, the CAI approach may be more in line with current dental students' learning expectations than the traditional scheduled laboratories.

CAI has the potential to supplement faculty instruction, especially when there is a need for repeated demonstration of technique. This feature is particularly attractive in a time of faculty shortages. ${ }^{15}$ DVD technology also allows students to customize acquisition of information. Students may view the DVD in its entirety once or multiple times, they may select parts to review again and again, and they can progress through the DVD at their own pace.

Crossover of information between the DVDonly and traditional groups was a potential problem. This was reduced by instructing students not to share teaching materials. Faculty members were also told to provide instruction and feedback only to students in the traditional group. Faculty members were aware of which students were in the traditional group (or non-study participants) since these students reported to scheduled carving laboratory sessions for two weeks. But the faculty graders were blinded as to which group students belonged since all of the competency wax carvings were identified only by a numeric code.

Another potential limitation of this study was selection bias in spite of a randomized selection process. More students in the DVD-only group responded that they had extensive experience with computer and DVD technologies. It may be that the randomization process failed and that more students in the DVD-only group had more experience with these technologies. This result may have influenced their experience and perceptions of their teaching modality although this finding may be a result of the cross-sectional study design in that students' perceptions could have been influenced by their group assignment.
According to our data and other reports, ${ }^{16-19}$ student learning needs may be best met by merging CAI with traditional laboratory teaching. Future offerings of the dental anatomy wax carving course will employ select CAI technology to demonstrate technique, with optional laboratory time when faculty will be available to facilitate feedback and promote students' self-assessment skills. This change will likely satisfy contemporary dental students' learning styles in which independent, self-paced, anytime anywhere learning is appealing. Dental school resources will also be better utilized by freeing faculty and laboratory space for other teaching endeavors. Furthermore, by changing the faculty members' focus from repeatedly demonstrating techniques to facilitating evaluation skills, students' learning and ability to self-assess may improve.

\section{Acknowledgments}

The authors would like to thank Drs. Eduardo Gomez and Hau Ngo for developing and creating the wax carving technique DVD.

\section{REFERENCES}

1. Atkinson R. Computerized instruction and the learning process. Am Psychol 1968;23:225-39.

2. Suppes P, Morningstar M. Computer-assisted instruction. Science 1968;166:343-50.

3. Rosenberg H, Grad HA, Matear DW. The effectiveness of computer-aided, self-instructional programs in dental education: a systematic review of the literature. J Dent Educ 2003;67(5):524-32.

4. Rosenberg H, Sander M, Posluns J. The effectiveness of computer-aided learning in teaching orthodontics: a review of the literature. Am J Orthod Dentofacial Orthop 2005;127(5):599-605.

5. Fouad AF, Burleson JA. Effectiveness of an endodontic diagnosis computer simulation program. J Dent Educ 1997;61(3):289-95.

6. Hobson RS, Carter NE, Hall FM, Atkins MJ. A study into the effectiveness of a text-based computer-assisted learning program in comparison with seminar teaching of orthodontics. Eur J Dent Educ 1998;2:154-09.

7. McDonough M, Marks IM. Teaching medical students exposure therapy for phobia/panic-randomized, controlled comparison of face-to-face tutorial in small groups vs. solo computer instruction. Med Educ 2002;36(5):412-7.

8. Sandoval VA, Dale RA, Hendricson WD, Alexander JB. A comparison of four simulation and instructional methods for endodontic review. J Dent Educ 1987;51(9):532-8.

9. Tira DE. Evaluation of a CAI course in a removable partial prosthodontics classification system. J Comput Based Instruct 1977;4:34-42.

10. Gega L, Norman IJ, Marks IM. Computer-aided vs. tutordelivered teaching of exposure therapy for phobia/panic: 
randomized controlled trial with pre-registration nursing students. Int J Nurs Stud 2007;44(3):397-405.

11. Bogacki RE, Best A, Abbey LM. Equivalence study of a dental anatomy computer-assisted learning program. J Dent Educ 2004;68(8):867-71.

12. Gunsolley JC, Elswick RK, Davenport JM. Equivalence and superiority testing in regeneration clinical trials. J Periodontol 1998;69:521-7.

13. Curtis DA, Lind SL, Dellinges M, Setia G, Finzen FC. Dental students' self-assessment of preclinical examinations. J Dent Educ 2008;72(3):265-77.

14. Evans A, McKenna C, Oliver M. Trainees' perspectives on the assessment and self-assessment of surgical skills. Assessment Eval Higher Educ 2005;30(2):163-74.

15. Haj-Ali R, Walker MP, Petrie CS, Steven J. Educational necessities to compensate for faculty shortages. J Dent Educ 2007;71(4):511-5.
16. Forman LJ, Pomerantz SC. Computer-assisted instruction: a survey on the attitudes of osteopathic medical students. J Am Osteopath Assoc 2006;106(9):571-8.

17. Burke JF, Gnall E, Umrudden Z, Kyaw M, Schick PK. Critical analysis of a computer-assisted tutorial on ECG interpretation and its ability to determine competency. Med Teach 2008;30(2):e41-9.

18. Eitner S, Holst S, Wichmann M, Karl M, Nkenke E, Schlegel A. Comparative study on interactive computer-aided-learning and computer-aided-testing in patient-based dental training in maxillofacial surgery. Eur J Dent Educ 2008;12(1):35-40.

19. Howerton WB Jr, Platin E, Ludlow J, Tyndall DA. The influence of computer-assisted instruction on acquiring early skills in intraoral radiography. J Dent Educ 2002;66(10):1154-8. 